\title{
HUBUNGAN KUALITAS FISIK RUMAH DENGAN KEJADIAN TBC PARU DI WILAYAH KERJA PUSKESMAS I DENPASAR SELATAN TAHUN 2018
}

\section{Ni Komang Suari Melinda Dewi ${ }^{1}$, Anysiah Elly Yulianti ${ }^{2}$}

\begin{abstract}
Indonesia is the second country with the highest population of Tuberculosis in the world after India. Tuberculosis is caused by Microbacterium tuberculosis wich transmitted through the airborne. One of the efforts for prevent the TBC transmitted is keeping the healthy quality physical of home. This research purposed to know the correlation between quality physical of home with lung TBC case at Puskesmas I South Denpasar working area. The types of this research is observasional retrospektif using case control design. Sampling procedures using total population sampling technique. The case group sample amount 34 patient with TBC in 2016 at Puskesmas I South Denpasar. The control grup sample amount 34 people who never suffer lung TBC and has same characteristics with the case group sample. Data collection using observation paper and analys statistic test using chi square method, continued with counting Coefficient Contigency (CC). Based on the chi square method result, showing the relation between lighting ( $p=0,001 C C=0,361)$, ventilation $(p=0,014 C C=0,286)$, humadity $(p=0,013 C C=0,290)$ dan temperature $(p=0,000 C C=0,246)$ of home with lung TBC. There are no relation between the number of occupants home $(p=0,086)$ and wall floor quality's $(p=0,088)$ with lung TBC case. Submitted suggestion in this research are 1) for community, please keep your attention for healthy and hygiene home, 2) for Puskesmas I South Denpasar, should be increased the health promotion about health housing wich related with Lung TBC.
\end{abstract}

Key words: risk factors, Tuberculosis

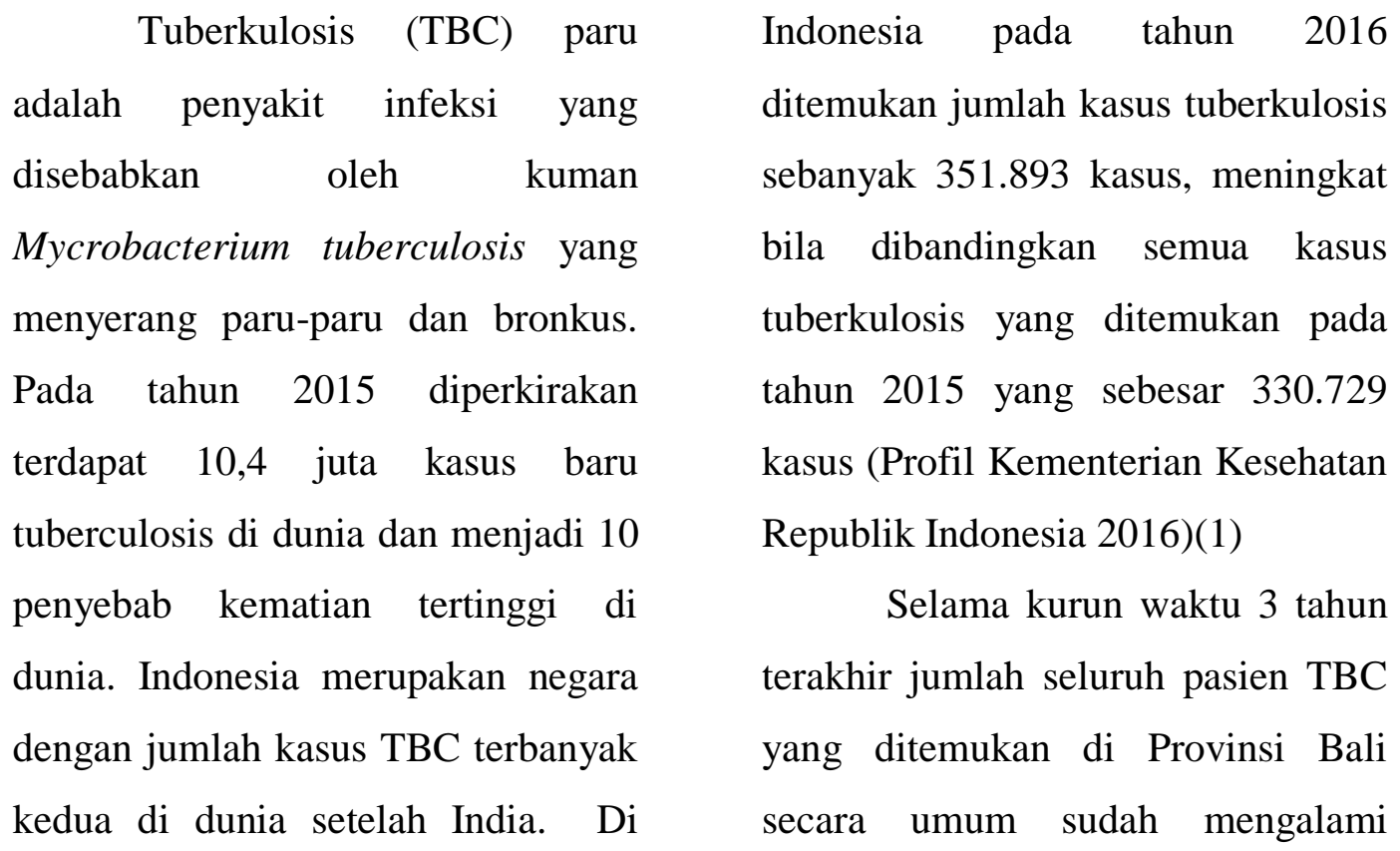


peningkatan walaupun tidak signifikan. Pada tahun 2016 jumlah seluruh kasus TBC yang ditemukan di Provinsi Bali adalah sebanyak 3.133 orang. Kota Denpasar merupakan kota dengan penemuan kasus TBC paru tertinggi di Bali (Profil Dinas Kesehatan Provinsi Bali 2016)(2). Pada tahun 2016 ditemukan 512 pasien BTA positif di Kota Denpasar dan Puskesmas di kota Denpasar dengan kasus TBC paru tertinggi terdapat di wilayah kerja Puskesmas I Denpasar Selatan, sedangkan kasus TBC paru terendah ditemukan di wilayah kerja Puskesmas IV Denpasar Selatan (Dinkes Kota Denpasar, 2017). Pada wilayah kerja Puskesmas I Denpasar Selatan ditemukan 34 kasus TBC paru pada tahun 2016. Kasus tertinggi sebanyak 16 orang terjadi di desa Sesetan yang terdiri dari 14 banjar kemudian disusul oleh desa Panjer yang terdiri dari 9 banjar dengan jumlah kejadian TBC yang ditemukan adalah sebanyak 10 orang, kasus terendah terjadi di desa Sidakarya yang terdiri dari 12 banjar dengan kasus yang ditemukan adalah 8 orang (Profil Puskesmas I Denpasar Selatan 2017).(3)
Penyakit infeksi kronik Tuberkulosis paru sudah sangat lama dikenal pada manusia, dulu penyakit ini tersebar luas diseluruh dunia tetapi sekarang sudah jarang ditemukan di Eropa dan Amerika Serikat karena perbaikan hygiene dan standar hidup. Salah satu upaya dalam perbaikan hygiene adalah dengan membangun rumah sehat bagi kehidupan (Sibuea dkk, 2009).(4) Rumah sehat adalah bangunan sebagai sarana atau tempat berlindung dan bernaung serta tempat untuk beristirahat sehingga menumbuhkan kehidupan yang sehat dalam fisik, rohani maupun sosial budaya. Agar rumah sebagai tempat tinggal dapat berfungsi dengan baik, maka pembangunannya harus disesuaikan dengan persyaratanpersyaratan untuk menciptakan rumah yang sehat. Salah satu persyaratan rumah sehat adalah dengen memenuhi persyaratan physiologis atau kualitas fisik rumah. Kualitas fisik rumah terdiri dari suhu, kelembaban, pencahayaan, ventilasi, kepadatan penghuni, kualitas dinding dan lantai (Sanropie dkk, 2005). (5)

Berdasarkan hasil wawancara dengan petugas Kesehatan 
Lingkungan Puskesmas I Denpasar Selatan, diketahui bahwa pemeriksaan kualitas fisik rumah pada rumah penderita TBC paru di Wilayah Kerja Puskesmas I Denpasar Selatan belum pernah dilakukan. Berdasarkan hasil penelitian Hamidah dkk (2015)(6) didapatkan bahwa ada hubungan yang signifikan antara kepadatan hunian rumah $(p$-value $=0,001)$, kelembaban $(p$-value $=0,000)$, luas ventilasi rumah $(p$-value $=0,002)$, dan pencahayaan $(p$-value $=0,000)$ dengan kejadian penyakit tuberkulosis paru di Wilayah Kerja Puskesmas Perawatan Siko Kecamatan Ternate Utara Kota Ternate Provinsi Maluku Utara. Dari hasil penelitian Anggraeni dkk (2015)(7) penelitian menunjukkan ada hubungan kualitas fisik rumah dengan kejadian TBC paru di Wilayah Kerja Puskesmas Gondanglegi Kecamatan Gondanglegi Kabupaten Malang.

\section{Metode}

Jenis penelitian yang dipergunakan oleh peneliti adalah observasional retrospektif dengan rancangan kasus-kontrol (case control). Populasi dalam penelitian ini adalah masyarakat di Wilayah Kerja Puskesmas I Denpasar Selatan. Sampel pada penelitian ini dibagi menjadi dua kelompok yaitu kelompok kasus dan kelompok kontrol. Kelompok kasus dalam penelitian ini adalah seluruh penderita TBC paru dengan BTA positif yang melakukan pengobatan dan tercatat di data Puskesmas I Denpasar Selatan Tahun 2016 berjumlah 34 orang. Kelompok kontrol dalam penelitian ini adalah masyarakat yang beresiko terserang TBC paru di Wilayah Kerja Puskesmas I Denpasar Selatan dan memiliki karakteristik jenis kelamin, umur, pendidikan dan pekerjaan yang sama atau hampir sama dengan kelompok kasus dan berjumlah 34 orang.

Teknik sampling pada penelitian ini adalah menggunakan teknik total population sampling. Cara pengumpulan data dikumpulkan melalui kunjungan rumah dengan melakukan wawancara, observasi terhadap rumah responden dengan menggunakan lembar observasi dan pengukuran dengan menggunakan alat sesuai dengan parameter yang 
diukur. Analisa data dalam menggunakan metode analisis Chi penelitiam ini yaitu analisa univariat Square (X2). Selanjutnya untuk dan bivariat. Analisis univariat dalam penelitian ini adalah pengukuran kualitas fisik rumah yang mengacu pada Keputusan Menteri Kesehatan Republik Indonesia No. 829/Menkes/SK/VII/1999(8) tentang persyaratan kesehatan perumahan. Pada analisis bivariat ini mengetahui besarnya hubungan antar variabel tersebut dilakukan perhitungan Coefficient Contingency $(C C)$, sedangkan untuk melihat besarnya resiko pada variabel yang telah diteliti digunakan analisis $O d d s$ Ratio (OR) dengan Confidence Interval (CI) $95 \%$.

\section{Hasil Penelitian}

1. Hubungan Pencahayaan Alami Rumah dengan Kejadian TBC Paru

Tabel 1

Analisis Hubungan Pencahayaan Alami Rumah dengan Kejadian TBC Paru di Wilayah Kerja Puskesmas I Denpasar Selatan

\begin{tabular}{|c|c|c|c|c|c|c|c|}
\hline \multirow{3}{*}{ Pencahayaan } & \multicolumn{4}{|c|}{ Kejadian TBC Paru } & \multirow{2}{*}{\multicolumn{2}{|c|}{ Total }} & $\mathbf{P}$ \\
\hline & \multicolumn{2}{|c|}{ Kasus } & \multicolumn{2}{|c|}{ Kontrol } & & & \multirow{2}{*}{ Value } \\
\hline & $\mathbf{n}$ & $\%$ & $\mathbf{n}$ & $\%$ & $\mathbf{n}$ & $\%$ & \\
\hline Memenuhi Syarat & 13 & 33,3 & 26 & 66,7 & 39 & 100 & \\
\hline Tidak Memenuhi Syarat & 21 & 72,4 & 8 & 27,6 & 29 & 100 & 0,001 \\
\hline Total & 34 & 50 & 34 & 50 & 68 & 100 & \\
\hline
\end{tabular}

Berdasarkan uji Chi square diketahui nilai propabilitas $(\mathrm{p})=0,001<\alpha=0,05$ jadi Ho ditolak dan Ha diterima yang berarti ada hubungan antara pencahayaan alami rumah dengan kejadian TBC Paru. Berdasarkan perhitungan Coeffisient Contingency $(C C)$ didapatkan hasil 0,361 yang artinya terdapat hubungan yang rendah antara pencahayaan alami rumah dengan kejadian TBC Paru sedangkan berdasarkan perhitungan Odds Ratio (OR) didapatkan hasil 0,190. 
2. Hubungan Ventilasi Rumah dengan Kejadian TBC Paru

Tabel 2

Analisis Hubungan Ventilasi Rumah dengan Kejadian TBC Paru di Wilayah

Kerja Puskesmas I Denpasar Selatan

\begin{tabular}{|c|c|c|c|c|c|c|c|}
\hline \multirow{3}{*}{ Ventilasi } & \multicolumn{4}{|c|}{ Kejadian TBC Paru } & \multirow{2}{*}{\multicolumn{2}{|c|}{ Total }} & $\mathbf{P}$ \\
\hline & \multicolumn{2}{|c|}{ Kasus } & \multicolumn{2}{|c|}{ Kontrol } & & & \multirow{2}{*}{ Value } \\
\hline & $\mathbf{n}$ & $\%$ & $\mathbf{n}$ & $\%$ & $\mathbf{n}$ & $\%$ & \\
\hline Memenuhi Syarat & 15 & 37,5 & 25 & 62,5 & 40 & 100 & \\
\hline Tidak Memenuhi Syarat & 19 & 67,9 & 9 & 32,1 & 28 & 100 & 0,014 \\
\hline Total & 34 & 50 & 34 & 50 & 68 & 100 & \\
\hline
\end{tabular}

Berdasarkan uji Chi square diketahui nilai propabilitas $(p)=0,014<\alpha=0,05$ jadi Ho ditolak dan Ha diterima yang berarti ada hubungan antara ventilasi rumah dengan kejadian TBC Paru. Berdasarkan perhitungan Coeffisient Contingency (CC) didapatkan hasil hubungan yang rendah antara ventilasi rumah dan kejadian TBC Paru dengan nilai $\mathrm{CC}=0,286$, sedangkan berdasarkan perhitungan Odds Ratio $(O R)$ didapatkan hasil 0,284

3. Hubungan Kelembaban Rumah dengan Kejadian TBC Paru

Tabel 3

Analisis Hubungan Kelembaban Rumah dengan Kejadian TBC Paru di Wilayah Kerja Puskesmas I Denpasar Selatan

\begin{tabular}{|c|c|c|c|c|c|c|c|}
\hline \multirow{3}{*}{ Kelembaban } & \multicolumn{4}{|c|}{ Kejadian TBC Paru } & \multirow{2}{*}{\multicolumn{2}{|c|}{ Total }} & $\mathbf{P}$ \\
\hline & \multicolumn{2}{|c|}{ Kasus } & \multicolumn{2}{|c|}{ Kontrol } & & & \multirow{2}{*}{ Value } \\
\hline & $\mathbf{n}$ & $\%$ & $\mathbf{n}$ & $\%$ & $\mathbf{n}$ & $\%$ & \\
\hline Memenuhi Syarat & 16 & 38,1 & 26 & 61,9 & 42 & 100 & \\
\hline Tidak Memenuhi Syarat & 18 & 69,2 & 8 & 30,8 & 26 & 100 & 0,013 \\
\hline Total & 34 & 50 & 34 & 50 & 68 & 100 & \\
\hline
\end{tabular}

Berdasarkan uji Chi square diketahui nilai propabilitas $(p)=0,013<\alpha=0,05$ jadi Ho ditolak dan Ha diterima yang berarti ada hubungan antara kelembaban rumah dengan kejadian TBC Paru. Besar hubungan antara variabel terikat dan variabel bebas dapat diketahui dengan melakukan perhitungan Coeffisient 
Contingency $(C C)$ dan didapatkan hasil hubungan yang rendah antara kelembaban rumah dan kejadian TBC Paru dengan nilai Coeffisient Contigency $(C C)=0,290$, sedangkan berdasarkan perhitungan Odds Ratio didapatkan hasil 0,274

4. Hubungan Suhu Rumah dengan Kejadian TBC Paru

Tabel 4

Analisis Hubungan Suhu Rumah dengan Kejadian TBC Paru di Wilayah Kerja Puskesmas I Denpasar Selatan

\begin{tabular}{|c|c|c|c|c|c|c|c|}
\hline \multirow{3}{*}{ Suhu } & \multicolumn{4}{|c|}{ Kejadian TBC Paru } & \multirow{2}{*}{\multicolumn{2}{|c|}{ Total }} & $\mathbf{P}$ \\
\hline & \multicolumn{2}{|c|}{ Kasus } & \multicolumn{2}{|c|}{ Kontrol } & & & \multirow{2}{*}{ Value } \\
\hline & $\mathbf{n}$ & $\%$ & $\mathbf{n}$ & $\%$ & $\mathbf{n}$ & $\%$ & \\
\hline Memenuhi Syarat & 10 & 27,8 & 26 & 72,2 & 36 & 100 & \\
\hline Tidak Memenuhi Syarat & 24 & 75,0 & 8 & 25,0 & 32 & 100 & 0,000 \\
\hline Total & 34 & 50 & 34 & 50 & 68 & 100 & \\
\hline
\end{tabular}

Berdasarkan uji Chi square diketahui nilai propabilitas $(\mathrm{p})=0,000<\alpha=0,05$ jadi Ho ditolak dan Ha diterima yang berarti ada hubungan antara suhu rumah dengan kejadian TBC Paru. Berdasarkan uji Chi square diketahui nilai propabilitas $(\mathrm{p})=0,000<\alpha=0,05$ jadi Ho ditolak dan Ha diterima yang berarti ada hubungan antara suhu rumah dengan kejadian TBC Paru. Besar hubungan antara variabel terikat dan variabel bebas dapat diketahui dengan melakukan perhitungan Coeffisient Contingency (CC) dan didapatkan hasil hubungan yang sedang antara suhu rumah dan kejadian TBC Paru dengan nilai CC adalah 0,426 sedangkan berdasarkan perhitungan Odds Ratio didapatkan hasil 0,128. 
5. Hubungan Kepadatan Penghuni Rumah dengan Kejadian TBC Paru

Tabel 5

Analisis Hubungan Kepadatan Penghuni Rumah dengan Kejadian Penyakit TBC Paru di Wilayah Kerja Puskesmas I Denpasar Selatan

\begin{tabular}{|c|c|c|c|c|c|c|c|}
\hline \multirow{3}{*}{ Kepadatan Penghuni } & \multicolumn{4}{|c|}{ Kejadian TBC Paru } & \multirow{2}{*}{\multicolumn{2}{|c|}{ Total }} & $\mathbf{P}$ \\
\hline & \multicolumn{2}{|c|}{ Kasus } & \multicolumn{2}{|c|}{ Kontrol } & & & \multirow{2}{*}{ Value } \\
\hline & $\mathbf{n}$ & $\%$ & $\mathbf{n}$ & $\%$ & $\mathbf{n}$ & $\%$ & \\
\hline Memenuhi Syarat & 11 & 37,9 & 18 & 62,1 & 29 & 100 & \\
\hline Tidak Memenuhi Syarat & 23 & 59,0 & 16 & 41,0 & 39 & 100 & 0,086 \\
\hline Total & 34 & 50 & 34 & 50 & 68 & 100 & \\
\hline
\end{tabular}

Berdasarkan uji Chi square diketahui nilai propabilitas $(\mathrm{p})=0,086>\alpha=0,05$ jadi Ha ditolak dan Ho diterima yang berarti tidak ada hubungan antara kepadatan penghuni rumah dengan kejadian TBC Paru.

6. Hubungan Kualitas Dinding dan Lantai Rumah dengan Kejadian TBC Paru

Tabel 6

Analisis Hubungan Kualitas Dinding dan Lantai Rumah dengan Kejadian

Penyakit TBC Paru di Wilayah Kerja Puskesmas I Denpasar Selatan

\begin{tabular}{ccccccccc}
\hline \multirow{2}{*}{$\begin{array}{c}\text { Kualitas Dinding dan } \\
\text { Lantai }\end{array}$} & \multicolumn{4}{c}{ Kejadian TBC Paru } & \multirow{2}{*}{ Total } & & P \\
\cline { 2 - 5 } \cline { 5 - 6 } & \multicolumn{2}{c}{ Kasus } & \multicolumn{2}{c}{ Kontrol } & & \multirow{2}{*}{ Value } \\
\cline { 2 - 6 } & $\mathbf{n}$ & $\mathbf{\%}$ & $\mathbf{n}$ & $\mathbf{\%}$ & $\mathbf{n}$ & $\mathbf{\%}$ & \\
\hline Memenuhi Syarat & 12 & 38,7 & 19 & 61,3 & 31 & 100 & \\
Tidak Memenuhi Syarat & 22 & 59,5 & 15 & 40,5 & 37 & 100 & \multirow{2}{*}{0,088} \\
\hline Total & 34 & 50 & 34 & 50 & 68 & 100 & \\
\hline
\end{tabular}

Berdasarkan uji Chi square diketahui nilai propabilitas $(\mathrm{p})=0,088>\alpha=0,05$ jadi Ha ditolak dan Ho diterima yang berarti tidak ada hubungan antara kualitas dinding dan lantai rumah dengan kejadian TBC Paru. 
PEMBAHASAN

\section{Hubungan Pencahayaan}

Alami Rumah dengan

Kejadian TBC Paru

Berdasarkan penelitian diperoleh hasil pengukuran penerangan alami rumah dengan kategori memenuhi persyaratan sebanyak $57,3 \%$ dan dengan kategori tidak memenuhi syarat sebanyak $42,7 \%$. Pencahayaan yang tidak memenuhi persyaratan pada beberapa rumah di Wilayah Kerja Puskesmas I Denpasar Selatan disebabkan oleh sinar matahari yang tidak masuk secara optimal karena sinar matahari terhalang oleh bangunan yang berada di sekeliling rumah, mengingat kondisi setiap bangunan rumah di Wilayah Kerja Puskesmas I Denpasar Selatan berjarak cukup dekat. Selain itu kurangnya akses atau jalan yang memungkinkan untuk masuknya cahaya matahari ke dalam rumah serta tata letak ruang kamar tidur yang mempengaruhi tingkat pencahayaan rumah di Wilayah Kerja Puskesmas I Denpasar Selatan. Menurut Kepmenkes 829 Tahun 1999 pencahayaan dalam ruang rumah diusahakan agar sesuai dengan kebutuhan untuk melihat benda sekitar dan membaca berdasarkan persyaratan minimal 60 Lux. Pencahayaan alam diperoleh dengan masuknya sinar matahari ke dalam ruangan melalui jendela, celah-celah dan bagian-bagian bangunan yang terbuka. Sinar ini sebaiknya tidak terhalang oleh bangunan, pohon-pohon maupun tembok pagar yang tinggi (Sanropie dkk, 2005).

Berdasarkan uji Chi square diketahui Ho ditolak dan Ha diterima yang berarti ada hubungan antara pencahayaan alami rumah dengan kejadian TBC Paru, hal ini sejalan dengan penelitian Rosiana (2013) dengan $\mathrm{p}$ value $=0,023$, Deny (2014) dengan $\mathrm{p}$ value $=0,032$, Azzahra $(2017)(9)$ dengan $\mathrm{p}$ value $=0,010$, dan Syafri (2015)(10) dengan p value $=0,003$ yang menyatakan bahwa adanya hubungan antara pencahayaan alami dengan kejadian TBC Paru. Karena basil TBC tidak tahan cahaya matahari, kemungkinan pemularan di bawah terik matahari sangat kecil. Oleh karena itu pencahayaan alami rumah yang memenuhi syarat dapat mengurangi penyebab penyebaran penyakit TBC Paru. Pemenuhan kebutuhan- 
kebutuhan cahaya untuk penerangan alami sangat ditentukan oleh letak dan lebar jendela (Danusantoso, 2013).(11)

Bagi rumah yang pencahayaan alaminya masih kurang atau tidak memenuhi syarat sebaiknya dilakukan dengan mengganti sebagian genteng rumah dengan genteng kaca atau asbes plastik dan melobangi plafon pada ruangan tepat dibawah genteng kaca atau asbes plastik tersebut agar sinar dari atas dapat masuk dan menyinari ruangan secara langsung. Untuk jangka panjang dapat juga dilakukan dengan penambahan lubang penghawaan seperti jendela yang dapat berfungsi ganda yaitu sebagai tempat masuknya cahaya matahari dan keluar masuknya udara (Sujana, 2013).

\section{Hubungan Ventilasi Rumah dengan Kejadian TBC Paru}

Berdasarkan penelitian yang dilakukan diperoleh hasil pengukuran ventilasi rumah dengan kategori memenuhi persyaratan sebanyak $58,8 \%$ dan dengan kategori tidak memenuhi syarat sebanyak 41,2 \%. Menurut Kepmenkes Republik Indonesia No.
829 Tahun 1999 tentang persyaratan kesehatan perumahan, rumah harus dilengkapi dengan ventilasi dengan luas minimal $10 \%$ dari luas lantai. Ventilasi yang tidak memenuhi persyaratan pada beberapa rumah di Wilayah Kerja Puskesmas I Denpasar Selatan disebabkan karena luas ventilasi yang kurang dari $10 \%$ luas lantai, beberapa rumah di Wilayah Kerja Puskesmas I Denpasar Selatan memiliki ventilasi yang kurang baik yaitu seperti ventilasi dengan luas lubang hiasan yang kecil sehingga menyebabkan suplai udara segar yang masuk ke dalam rumah tidak tercukupi dan pengeluaran udara kotor ke luar rumah juga tidak maksimal.

Berdasarkan uji Chi square diketahui nilai propabilitas $(\mathrm{p})=$ $0,014<\alpha=0,05$ jadi Ho ditolak dan $\mathrm{Ha}$ diterima yang berarti ada hubungan antara ventilasi rumah dengan kejadian TBC Paru, hal ini sejalan dengan penelitian Sinaga dkk (2016) dengan $\mathrm{p}$ value $=0,000$, Deny (2014) dengan $\mathrm{p}$ value $=0,020$, Azzahra (2017) dengan $\mathrm{p}$ value $=$ 0,0001 dan Putra (2011) dengan $\mathrm{p}$ value 0,016 yang menyatakan bahwa adanya hubungan antara ventilasi 
rumah dengan kejadian TBC Paru. Kurangnya ventilasi akan menyebabkan kelembaban udara di dalam ruangan meningkat akibat terperangkapnya uap air yang berasal dari penguapan cairan dari kulit atau melalui penyerapan uap air yang berasal dari luar rumah. Ventilasi juga dapat mempermudah masuknya sinar matahari ke dalam rumah, paparan sinar matahari yang merupakan sinar ultraviolet dapat membunuh bakteri-bakteri patogen termasuk Mycobacterium tuberculosis karena sifat bakteri tersebut yang tidak mampu bertahan hidup jika terpapar sinar ultraviolet secara langsung (Sinaga dkk, 2016).(12) Upaya yang dapat dilakukan untuk mengatasi ventilasi yang kurang atau tidak memenuhi syarat yaitu dengan membuka jendela yang ada secara rutin setiap hari, membersihkan lubang ventilasi secara berkala dan membiarkan pintu setiap ruangan tetap terbuka pada siang hari saat penghuninya berada di rumah. Bila memungkinkan untuk jangka panjang dapat dilakukan dengan menambahkan lubang penghawaan seperti jendela dengan penempatan di tengah-tengah dinding dan tidak terhalang oleh bangunan lainnya agar terjadinya sirkulasi udara secara maksimal (Sujana dkk, 2013).(13)

\section{Hubungan Kelembaban}

\section{Rumah dengan Kejadian TBC}

\section{Paru}

Berdasarkan penelitian yang dilakukan diperoleh hasil pengukuran kelembaban rumah dengan kategori memenuhi persyaratan sebanyak 61,7 \% dan dengan kategori tidak memenuhi syarat sebanyak 38,3\%. Kelembaban yang tidak memenuhi persyaratan pada beberapa rumah di Wilayah Kerja Puskesmas I Denpasar Selatan disebabkan oleh ukuran ventilasi yang tidak memadai untuk terjadinya pertukaran udara secara optimal dan jendela rumah yang sering dibiarkan tertutup sehingga menghambat pertukaran udara di dalam ruangan tersebut. Selain itu sinar matahari yang tidak masuk secara optimal karena sinar matahari terhalang oleh bangunan yang berada di sekeliling rumah, mengingat kondisi setiap bangunan rumah di Wilayah Kerja Puskesmas I Denpasar Selatan berjarak cukup dekat. Pada Kepmenkes RI No No. 829 Tahun 
1999 tentang persyaratan kesehatan perumahan, persyaratan kelembaban rumah adalah berkisar $40 \%-60 \%$. Kelembaban yang terlalu tinggi maupun rendah dapat menyebabkan suburnya pertumbuhan mikroorganisme.

Berdasarkan uji Chi square diketahui nilai propabilitas $(\mathrm{p})=$ $0,013<\alpha=0,05$ Ho ditolak dan Ha diterima yang berarti ada hubungan antara kelembaban rumah dengan kejadian TBC Paru di Wilayah Kerja Puskesmas I Denpasar Selatan, hal ini sejalan dengan penelitian Rosiana (2013) dengan $\mathrm{p}$ value $=0,032$, Azzahra (2017) dengan $\mathrm{p}$ value $=$ 0,004 dan Batti (2013) dengan $\mathrm{p}$ value $=0,009$ yang menyatakan bahwa adanya hubungan antara kelembaban dengan kejadian TBC Paru. Kelembaban yang tinggi dapat meningkatkan berkembangnya bakteri penyebab penyakit. Salah satunya adalah bakteri Mycobakterium tuberkulosis. Upaya yang dapat dilakukan untuk mengatasi rumah dengan ruangan yang kelembabannya tidak memenuhi syarat yaitu dengan memasang humidifier serta membuka jendela setiap hari dan membiarkan pintu rumah tetap terbuka pada siang hari selama penghuninya ada di rumah agar terjadi sirkulasi udara secara maksimal serta (Sujana dkk, 2013).

\section{Hubungan Suhu Rumah dengan Kejadian TBC Paru}

Berdasarkan penelitian yang dilakukan diperoleh hasil pengukuran suhu rumah dengan kategori memenuhi persyaratan sebanyak 52,9 \% dan dengan kategori tidak memenuhi syarat sebanyak $47,1 \%$. Suhu yang tidak memenuhi persyaratan pada beberapa rumah di Wilayah Kerja Puskesmas I Denpasar Selatan disebabkan oleh ukuran ventilasi yang tidak memadai untuk terjadinya pertukaran udara secara optimal dan jendela rumah yang sering dibiarkan tertutup sehingga menghambat pertukaran udara di dalam ruangan tersebut. Berdasarkan Kepmenkes No. 829/ Menkes/SK/VII/1999, suhu ruangan dalam rumah yang ideal yaitu berkisar antara $18-30^{\circ} \mathrm{C}$ Suhu dalam suatu ruangan dipengaruhi oleh suhu udara luar, pergerakan udara, dan kelembaban suhu ruangan. Suhu juga berpengaruh terhadap transmisi atau penularan 
penyakit yaitu bakteri lantai rumah. Adanya sirkulasi udara Mycobacterium tuberculosis akan yang baik diharapkan dapat menjaga berkembang biak optimum apabila suhu tersedia dalam jumlah yang optimum untuk kehidupannya.

Berdasarkan uji Chi square diketahui nilai propabilitas $(\mathrm{p})=$ $0,000<\alpha=0,05$ Ho ditolak dan Ha diterima yang berarti ada hubungan antara suhu rumah dengan kejadian TBC Paru di Wilayah Kerja Puskesmas I Denpasar Selatan, hal ini sejalan dengan penelitian Pratama dkk (2013)(14) dengan $\mathrm{p}$ value $=$ 0,004 yang menyatakan bahwa adanya hubungan antara kelembaban dengan kejadian TBC Paru. Keadaan suhu sangat berperan sekali pada pertumbuhan basil Mycobacterium tuberculosis, dimana laju pertumbuhan basil tersebut ditentukan berdasarkan suhu udara yang berada disekitarnya. Kondisi ini sangat terkait dengan sirkulasi udara di dalam rumah yang berhubungan langsung dengan udara luar rumah dan kurang memenuhi syarat kesehatan akibat dari luas ventilasi yang kurang dari 10\% luas lantai. Salah satu usaha untuk menjaga suhu rumah adalah memasang ventilasi yang cukup yaitu $10 \%$ dari luas suhu rumah dan meminimalisasi penularan tuberkulosis paru BTA positif dalam rumah (Azzahra, 2017).

\section{Hubungan}

Kepadatan

\section{Penghuni Rumah dengan Kejadian TBC Paru}

Berdasarkan penelitian yang dilakukan diperoleh kepadatan penghuni rumah dengan kategori memenuhi persyaratan sebanyak $42,65 \%$ dan dengan kategori tidak memenuhi syarat sebanyak 57,35 \% . Menurut Kepmenkes No 829 Tahun 1999 luas ruang tidur minimal $8 \mathrm{~m}^{2}$ dan tidak dianjurkan digunakan lebih dari dua orang tidur dalam satu ruang tidur, kecuali anak dibawah umur 5 tahun.

Berdasarkan uji Chi square diketahui nilai propabilitas $(\mathrm{p})=$ $0,086>\alpha=0,05$ Ho diterima dan Ha ditolak yang berarti tidak ada hubungan antara kepadatan penghuni rumah dengan kejadian TBC Paru di Wilayah Kerja Puskesmas I Denpasar Selatan, hal ini sejalan dengan penelitian Syafri (2015) dengan hasil penelitian konstan dan Pesik (2015)(15) dengan p value = 0,275 . Hasil penelitian ini berbeda 
dengan hasil penelitian Batti (2013)(16) dengan $\mathrm{p}$ value $=0,000$ yang menyatakan bahwa kepadatan hunian mempunyai hubungan bermakna dengan kejadian TBC Paru di Wilayah Kerja Puskesmas Wara Utara Kota. Perbedaan antara penelitian ini dengan penelitian yang dilakukan Batti yaitu metode yang digunakan. Pada penelitian yang dilakukan oleh Batti (2013) menggunakan metode cross sectional study dengan jumlah sampel sebanyak 100 orang, sedangkan pada penelitian ini sampel yang digunakan lebih sedikit yaitu 68 orang dengan metode yang digunakan case control yang membandingkan antara kelompok kasus TBC Paru sebanyak 34 responden dengan orang tidak menderita TBC Paru sebanyak 34 responden.

\section{Hubungan Kualitas Dinding dan Lantai Rumah dengan Kejadian TBC Paru}

Berdasarkan penelitian yang dilakukan di Wilayah Kerja Puskesmas I Denpasar Selatan diperoleh kualitas dinding dan lantai rumah dengan kategori memenuhi persyaratan sebanyak 45,59 \% dan dengan kategori tidak memenuhi syarat sebanyak 54,41\%. Menurut Kepmenkes No 829 Tahun 1999 dinding dan lantai rumah harus kedap air dan mudah dibersihkan. Dinding atau lantai yang diplester mengurangi masuknya udara sampai $25 \%$, cat mengurangi masuknya udara sampai 30\%, permadani mengurangi masuknya udara sampai $30 \%$ dan cat minyak mengurangi masuknya udara sampai 100\%, sehingga kualitas dinding dan lantai dari suatu rumah dapat mempengaruhi kelembaban rumah tersebut (Sanropie dkk, 2005).

Berdasarkan uji Chi square diketahui nilai propabilitas $(\mathrm{p})=$ $0,088>\alpha=0,05$ Ho diterima dan Ha ditolak yang berarti tidak ada hubungan antara kualitas dinding dan lantai rumah dengan kejadian $\mathrm{TBC}$ Paru di Wilayah Kerja Puskesmas I Denpasar Selatan, hal ini sejalan dengan penelitian Syafri (2015) dengan $\mathrm{p}$ value $=0,230$, Anggraeni $(2014)(17)$ dengan $\mathrm{p}$ value $=0,626$ dan Putra (2011)(18) dengan p value $=1,000$ yang menyatakan bahwa tidak ada hubungan antara kualitas dinding dan lantai dengan kejadian TBC Paru. Hasil penelitian ini berbeda dengan hasil penelitian 
Rosiana (2012)(19) yang dilakukan

di Wilayah Kerja Puskesmas

Kedungmundu Kota Semarang menyatakan ada hubungan yang signifikan antara jenis lantai dengan kejadian tuberkulosis paru ( $\mathrm{p}=$ 0,025), dan diperkirakan risiko jenis lantai yang tidak baik terkena tuberkulosis paru 22,15 kali dibandingkan rumah yang memiliki jenis lantai yang baik. Untuk perbedaan jenis lantai pada hasil penelitian yang didapat dengan penelitian Rosiana yaitu masih banyak rumah yang berlantaikan tanah sedangkan pada penelitian ini minimal rumah responden sudah di plester dan kondisi daerah didua tempat penelitian ini berbeda.

\section{Simpulan}

1. Ada hubungan pencahayaan alami rumah dengan kejadian TBC Paru di Wilayah Kerja Puskesmas I Denpasar Selatan dengan hasil uji Chi Square yaitu (p) $=0,001<\alpha=0,05$

2. Ada hubungan ventilasi rumah dengan kejadian TBC Paru di Wilayah Kerja Puskesmas I Denpasar Selatan dengan hasil uji
Chi square yaitu $(\mathrm{p})=0,014<\alpha$ $=0,05$

3. Ada hubungan kelembaban rumah dengan kejadian TBC Paru di Wilayah Kerja Puskesmas I Denpasar Selatan dengan hasil uji Chi square yaitu (p) $=0,013<\alpha=0,05$

4. Ada hubungan suhu rumah dengan kejadian TBC Paru di Wilayah Kerja Puskesmas I Denpasar Selatan dengan hasil uji Chi square yaitu $(\mathrm{p})=0,000<\alpha$ $=0,05$

5. Tidak ada hubungan kepadatan penghuni rumah dengan kejadian TBC Paru di Wilayah Kerja Puskesmas I Denpasar Selatan dengan hasil uji Chi square yaitu (p) $=0,086>\alpha=0,05$

6. Tidak ada hubungan kualitas dinding dan lantai rumah dengan kejadian TBC Paru di Wilayah Kerja Puskesmas I Denpasar Selatan dengan hasil uji Chi square yaitu $(\mathrm{p})=0,088>\alpha=$ 0,05 


\section{Saran}

1. Bagi masyarakat khususnya penderita TBC Paru dan keluarganya diharapkan agar menerapkan pola hidup bersih dan sehat dalam kehidupan sehari-hari untuk mencegah penularan penyakit TBC Paru dan agar dapat menjaga kondisi rumah tetap selalu dalam keadaan bersih dan sehat, misalnya adalah :

a. Bagi rumah yang pencahayaan alaminya masih kurang atau sebaiknya dilakukan dengan mengganti sebagian genteng rumah dengan genteng kaca atau asbes plastik selain itu dapat ditambahkan pencahayaan buatan seperti pemasangan lampu dan untuk jangka panjang dapat juga dilakukan dengan penambahan lubang penghawaan seperti jendela.

b. Upaya yang dapat dilakukan untuk mengatasi ventilasi, suhu dan kelembaban yang tidak memenuhi syarat yaitu dengan membuka jendela yang ada secara rutin setiap hari, membersihkan lubang ventilasi secara berkala dan membiarkan pintu setiap ruangan tetap terbuka pada siang hari saat penghuninya berada di rumah.

2. Disarankan kepada pihak Puskesmas I Denpasar Selatan sebaiknya lebih meningkatkan promosi kesehatan di bidang perumahan sehat khususnya kualitas fisik rumah yang berkaitan dengan penyakit TBC Paru dan tidak hanya menekankan pada pengobatan terhadap penderita, tetapi juga pada masyarakat lainnya tentang tindakan untuk mencegah penularan TBC Paru.

3. Bagi peneliti lain dapat menjadikan penelitian ini sebagai bahan acuan untuk melakukan penelitian selanjutnya.

\section{Daftar Pustaka}

1. Kepmenkes RI. Profil

Kementerian Kesehatan

Republik Indonesia Tahun 2016. 2016;

2. Dinkes Provinsi Bali. Profil Dinas Kesehatan Provinsi Bali Tahun 2016. 2016; 
3. I PD. Profil Puskesmas I

Denpasar Selatan Tahun 2016.

2016;

4. Sibuea WH dkk. Ilmu

Penyakit Dalam. Jakarta :

Rineka Cipta. 2009;

5. Sanropie D dkk. Pengawasan

Penyehatan Lingkungan

Pemukiman. Jakarta :

Departemen Kesehatan RI

Pusat Pendidikan Tenaga

Kesehatan. 2005;

6. Hamidah dkk. Hubungan

Kualitas Lingkungan Fisik

Rumah Dengan Kejadian

Tuberkulosis Paru Di Wilayah

Kerja Puskesmas Perawatan

Siko Kecamatan Ternate Utara

Kota Ternate Provinsi Maluku

Utara. 2015;

7. Anggraeni SK dkk. Hubungan

Kualitas Lingkungan Fisik

Rumah Dan Perilaku

Kesehatan Dengan Kejadian

Tb Paru di Wilayah Kerja

Puskesmas Gondanglegi

Kecamatan Gondanglegi

Kabupaten Malang. Jurnal

Kesehatan Masyarakat.

Volume 3 Nomor 1 Januari

2015 (ISSN : 2356 - 3346).

Univers. Kesehat Masy.
$2015 ; 3$

8. Kepmenkes RI. Keputusan

Menteri Kesehatan Republik

Indonesia Nomor

829/MENKES/SK/VII/1999

tentang Persyaratan Kesehatan

Perumahan. 1999;

9. Azzahra Z. Faktor-Faktor

Yang Mempengaruhi Kejadian

Penyakit Tuberkulosis Paru di

Wilayah Kerja Puskesmas

Mulyorejo Kecamatan

Sunggal Kabupaten Deli

Serdang Tahun 2017. Skripsi.

Fakultas Kesehatan

Masyarakat Universitas

Sumatera Utara Medan. 2017;

10. Syafri AK. Hubungan Kondisi

Fisik Rumah Dengan Kejadian

Tuberkulosis Paru Di Wilayah

Kerja Puskesmas Ngemplak

Boyolali. Jurnal Skripsi.

Program Studi Kesehatan

Masyarakat Fakultas Ilmu

Kesehatan Universitas

Muhammadiyah Surakarta.

2015;

11. Danusantoso H. Buku Saku

Ilmu Penyalit Paru. Edisi 2.

Jakarta : ECG. 2013. 
12. Sinaga F dkk. Hubungan

Kondisi Ventilasi Rumah dengan Kejadian TB Paru di

Wilayah Puskesmas Kelayan

Timur. Skripsi. Jurnal Berkala

Kedokteran, Vol.12, No.2, Sep

2016:279-288. Fakultas

Kedokteran, Universitas

Lambung Mangkurat

Banjarmasin. Berk Kedokt.

2016;12.

13. Sujana IK dkk. Pengaruh

Sanitasi Rumah Terhadap

Kejadian Penyakit TB Paru di

Wilayah Kerja UPT

Puskesmas Mengwi I Tahun

2013. Jurnal Kesehatan

Lingkungan. Vol 4 No 1 Mei

2014 : 93-98. Politenik

Kesehatan Denpasar. Kesehat

Lingkung. 2014;4.

14. Pratama B. Karakteristik

Lingkungan Fisik Rumah

Dengan Kejadian Tb Paru.

Skripsi. Fakultas Kedokteran

Universitas Lambung

Mangkurat. 2013;

15. Pesik DN. Hubungan Antara

Kepadatan Hunian Dan

Ventilasi Rumah dengan

Kejadian Penyakit

Tuberkulosis Paru Pada Pasien
Rawat Jalan di Puskesmas

Tumpaan Kabupaten

Minahasa Selatan. Skripsi.

Fakultas Kesehatan

Masyarakat Universitas Sam

Ratulangi. 2015;

16. Batti HTS. Analisis Hubungan

Antara Kondisi Ventilasi,

Kepadatan Hunian,

Kelembaban Udara, Suhu,

Dan Pencahayaan Alami

Rumah Dengan Kejadian

Tuberkulosis Paru di Wilayah

Kerja Puskesmas Wara Utara

Kota Palopo. Skripsi. Fakultas

Kesehatan Masyarakat

Universitas Sam R. 2013;

17. Angraeni RP. Hubungan

Antara Kondisi Fisik Rumah

Dengan Kejadian

Tuberkulosis Paru Bta Positif

Di Puskesmas 23 Ilir

Palembang Tahun 2014. Tesis.

Dosen Program Studi Ilmu

Keperawatan Sekolah Tinggi

Ilmu Kesehatan Bina Husada

Palembang. 2014; 
18. Putra NR. . Hubungan

Perilaku dan Kondisi Sanitasi

Rumah dengan Kejadian TB

Paru di Kota Solok Tahun

2011. Skripsi. Program Studi

Ilmu Kesehatan Masyarakat

Fakultas Kedokteran

Universitas Andalas Padang.

2011;

19. Rosiana AM. Hubungan

Antara Kondisi Fisik Rumah

Dengan Kejadian

Tuberkulosis Paru di Wilayah

Kerja Puskesmas

Kedungmundu Kota

Semarang. Skripsi. Jurusan

Ilmu Kesehatan Masyarakat,

Fakultas Ilmu Keolahragaan,

Universitas Negeri Semarang,

Indonesia. 2012; 